\title{
ANÁLISE DE PARÂMETROS FÍSICO QUÍMICOS DE ÁGUAS SUBTERRÂNEAS DA ZONA LESTE DE PRESIDENTE PRUDENTE NO SEGUNDO SEMESTRE DE 2018
}

\section{PHYSICAL AND CHEMICAL GROUNDWATER ANALYSIS OF PRESIDENTE PRUDENTE/SP EASTERN ZONE DURING SECOND HALF OF 2018}

Fernando Martinez Hungaro ${ }^{1}$, Marcelo Rodrigo Alves ${ }^{1}$, Patricia Alexandra Antunes ${ }^{1}$, Daniel Ângelo Macena ${ }^{2}$, Naiara Maria Pavani ${ }^{1}$

${ }^{1}$ Universidade do Oeste Paulista - UNOESTE. ${ }^{2}$ Universidade Virtual do Estado de São Paulo - UNIVESP.

E-mail: fmhungaro@gmail.com

RESUMO - O objetivo deste trabalho foi verificar o processo de urbanização prudentino no sentido da zona leste em sua relação com a indisponibilidade de pleno saneamento básico, levando a um quadro de contaminação das águas subterrâneas. Para tanto, utilizou-se, como indicadores da qualidade da água, parâmetros químicos e microbiológicos como o pH, condutividade, concentração de nitrato e coliformes fecais e totais. A pesquisa se pautou, em sua metodologia, por uma análise bibliográfica acerca do problema ora delineado, posteriormente se desenvolvendo mediante pesquisa experimental realizada nas regiões periféricas da zona leste prudentina. Assim, obteve-se resultados que demonstram a presença de compostos químicos e microbiológicos indesejáveis, com enfoque da inadequação quanto ao nitrogênio albuminoide e coliformes fecais e totais.

Palavras-chave: águas subterrâneas; urbanização; uso da água.

ABSTRACT - This work objective was to verify the process of Presidente Prudente urbanization related to the unavailability of full sanitation, which was able to develop a contamination of groundwater, using as indicators of water quality, chemical and microbiological parameters such as $\mathrm{pH}$, conductivity, nitrate concentration as well as fecal and total coliforms. In order to do so, the research was based in its methodology by a bibliographical analysis about the problem outlined in this work, and later developed through experimental research carried out in the peripheral regions located on the eastern zone of the city. Thus, there was obtained results that demonstrate the presence of undesirable chemical and microbiological compounds, focusing on the inadequacy of albuminous nitrogen and fecal and total coliforms.

Keywords: groundwaters; urbanization; water use. 


\section{INTRODUÇÃO E OBJETIVOS}

O município de Presidente ocidental do Estado de São Paulo, distante cerca de 560 quilômetros da capital do Estado e tendo atingido em 2016, segundo o Instituto Brasileiro de Geografia e Estatística (IBGE), a marca de 223.749 habitantes (IBGE, 2016). Consolida-se, portanto, como o município mais populoso do Oeste Paulista, sendo polo regional de mais de cinquenta municípios ao seu redor. Todavia, desde a sua fundação, em 14 de setembro de 1917, passou por colonização rápida e desenfreada, a qual trouxe a impossibilidade de um planejamento urbano para o seu crescimento e expansão sustentáveis.

Consequentemente, diante da expansão desordenada, determinados problemas surgiram e não foram devidamente tratados ou resolvidos ao longo dos anos. Especificamente no presente trabalho, o enfoque recai sobre a questão das águas subterrâneas no município, haja vista que a colonização, sem o devido planejamento, trouxe áreas com contaminação substancial e, por vezes, impróprias para uso e mesmo ingestão (HONDA, 2015, p. 67). Um dos problemas tratados como relevantes pela literatura até então existente, aponta em direção às elevadas concentrações do nitrato nas águas subterrâneas do município (GODOY et al., 2004, p. 2; VIEIRA, 2018, p. 62).

Justifica-se, assim, a pesquisa desenvolvida pela relevância do problema apontado, qual seja a contaminação ainda presente das águas subterrâneas de bairros específicos do município de Presidente Prudente/SP por compostos de nitrogênio, destacando-se o nitrato, em virtude das modalidades de colonização desenvolvidas ao longo dos praticamente cem anos de história do município.

Ante o exposto, a pesquisa teve o objetivo de avaliar a concentração de compostos químicos e microbiológicos em poços de zonas periféricas da região leste do município de Presidente Prudente, verificando como as concentrações dos compostos químicos e microbiológicos nas águas dos poços selecionados se encontram em relação aos níveis permitidos pelas legislações cabíveis.

\section{REVISÃO DE LITERATURA}

O município de Presidente Prudente, cuja fundação se deu em 1917, apresentava, em 2018, uma população estimada em 227.072 pessoas (IBGE, 2018 , p. 1 ), ao passo que o último Censo realizado mostrava, em 2010, uma população de 207.610 pessoas. Assim, comparando tal dado com a área territorial do município, que em 2017 totalizava 560,637 quilômetros quadrados, tem-se como resultado uma densidade demográfica de 368,89 habitantes por quilômetro quadrado.

Segundo Albano (2013, p. 81), Presidente Prudente se localiza na região conhecida como Alta Sorocabana, a oeste do Estado de São Paulo, estando próxima à divisa com o Estado do Mato Grosso do Sul quando se caminha a oeste e também ao Paraná quando se caminha em direção ao sul. Seu território está inserido nas Unidades de Gerenciamento de Recursos Hídricos do Peixe (UGRHI-21) e do Pontal do Paranapanema (UGRHI-22).

Por tais características, o município se caracteriza hoje como centro de um território que congrega mais de cinquenta municípios ao seu redor, os quais fazem uso dos recursos do município para cuidados com saúde, educação e mesmo lazer, principalmente aos finais de semana. Ademais, sendo um polo educacional regional, tanto para os ensinos fundamental e médio quanto para o ensino superior, a cidade apresenta uma população estudantil relevante, que povoa determinados bairros da cidade com estudantes vindo de outros municípios e mesmo Estados.

Neste contexto, cabe aqui a rememoração de alguns dados relevantes que caracterizam o município e suas peculiaridades, a saber (IBGE, 2018, p. 1):

- Arborização de vias públicas em 2010: 95,9\%; 
- Urbanização de vias públicas em 2010: 34,6\%;

- População ocupada em 2016: $34,6 \%$;

- PIB per capita em 2016: R\$ 33.101,42;

- Índice de Desenvolvimento Humano Municipal (IDHM-2010): 0,806;

- Esgotamento sanitário adequado em 2010: 98,1\%.

Para chegar até os dias atuais, o município passou por um processo de urbanização bastante específico. Como consequência, se desenvolveu o tema já tratado pela literatura específica como segregação socioespacial. Segundo Caldeira (2003, p. 20), trata-se de uma característica bastante relevante nas cidades, pois as normas e legislações que organizam o espaço urbano estão baseados em padrões de diferenciação e de separação.

Assim, o enfoque da expansão urbana no município de Presidente Prudente se deu a partir da década de 1970, em razão dos fatos detalhados, que derivam principalmente da aliança entre os interesses público e privado na exploração e oferta de imóveis.

As alterações legislativas que vieram, incluindo a promulgação da Constituição Federal de 1988, também contribuíram para a regularização e incorporação dos novos loteamentos, com a consequente migração da população das zonas centrais para áreas periféricas, destacando-se que não foi um movimento exclusivo das camadas de baixa renda, mas também das classes abastadas que seguiam em busca de loteamentos fechados de alto padrão, estes também dotados de certo grau de isolamento ao que até então se denominava região central de Presidente Prudente.

O resultado do processo de colonização não planejada atualmente se verifica em praticamente todas as áreas de políticas públicas. Em uma breve visualização, é possível verificar o trânsito que hoje se acumula em suas apertadas avenidas, a centralização da atividade econômica junto a determinadas áreas, em detrimento de outras que poderiam ser muito melhor utilizadas, entre outros importantes aspectos.

Em se tratando da contaminação das águas e seu posterior consumo, conforme a abordagem de Foster e Hirata (1988, p. 11), a contaminação dos aquíferos em áreas urbanas pode derivar de inúmeras fontes e razões. O saneamento in situ é apenas uma delas, havendo ainda a percolação de esgotos e resíduos sólidos (lixões e efluentes).

A alta densidade de tais fontes pode vir a gerar relevante carga poluidora para as águas subterrâneas.

Neste contexto, direcionando a abordagem ao saneamento in situ, pode-se dizer, conforme Wakida e Lerner (2005, p. 14), que tais sistemas são implantados naqueles locais em que a rede de esgotamento sanitário é inexistente ou insuficiente ao escoamento de resíduos, o que comumente vem a ocorrer em zonas não planejadas e na periferia das cidades. Em tais locais, portanto, torna-se hábito o uso de tanques sépticos para eliminação de esgotos.

Fazer uso de tanques sépticos (Figura 1) não seria problema, porém a sua manutenção precária, nos dizeres de Foster e Hirata $(1988$, p. 11) é o que vem a causar a contaminação das águas subterrâneas, haja vista que os efluentes lançados pelos sistemas de saneamento in situ são compostos por microrganismos, nutrientes compostos orgânicos sintéticos e sais, além de nitrato e cloreto. Estes últimos, segundo Varnier (2007, p. 8), são considerados parâmetros químicos adequados para indicar contaminação, justamente por sua mobilidade elevada e presença persistente. 
Figura 1. Exemplo de tanque séptico.

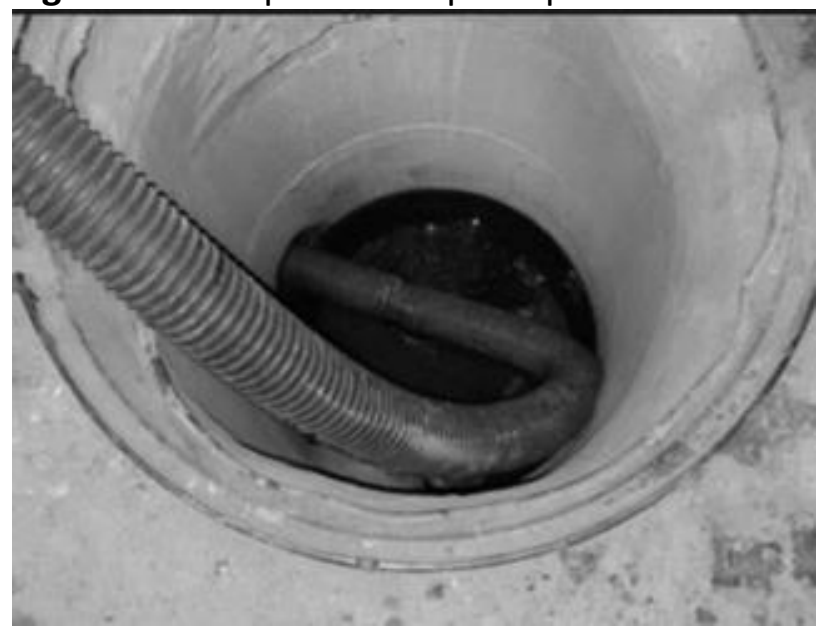

Fonte: (Higitec, 2017).

Portanto, a ligação entre tanques sépticos e poços torna-se elemento perigoso, haja vista a contaminação que deriva deste processo. A título exemplificativo, Godoy et al. (2004, p. 2) citam que, em pesquisa realizada através de uma estação piloto em Presidente Prudente, estudou-se a contaminação por nitrato do aquífero freático que foi derivada de vazamento de coletor de esgoto e de acúmulo de restos vegetais em torno e no interior de uma cacimba.

Assim, verifica-se que os dejetos derivados dos próprios habitantes de zonas sem saneamento básico acabam por retornar para seu consumo, o que ocorre mediante a integração entre tanques sépticos e poços.

Voltando a atenção para o caso específico de Presidente Prudente, considerando o que foi empiricamente evidenciado até o presente momento, é de se esperar a disponibilização também tardia do saneamento básico na zona leste prudentina, com a consequente priorização no uso do saneamento in situ, vem a conduzir, portanto, à existência de tanques sépticos e poços em maior número.

A análise empírica evidencia a existência de pontos ainda não dotados da presença de saneamento básico, nos termos do conceito trazido pela Lei $11.445 / 2007$, ou mesmo em que, ainda que ela exista, subsistem motivos para a preferência pelo uso do saneamento in situ, fato que vem a causar a contaminação das águas subterrâneas por elementos das mais variadas espécies, entre eles os compostos químicos que contêm o nitrogênio em sua composição, os quais são o enfoque do presente trabalho.

De modo complementar, cumpre ressaltar as abordagens semelhantes já desenvolvidas pela literatura especializada no tema. Nesse sentido, pertinente se faz apontar o trabalho de Cagnon (2003), o qual analisou o caso do município de Urânia/SP entre os anos de 1950 e 2000, procurando estabelecer uma relação entre a contaminação das águas subterrâneas do Sistema Aquífero Bauru por nitrato e os padrões de urbanização daquele local.

Em âmbito internacional, é relevante mencionar o trabalho realizado por Drake e Bauder (2005, p. 118), pesquisadores que estudaram o caso do município de Helena, no Estado de Montana, nos Estados Unidos. Em sua pesquisa, tais autores utilizaram o sistema de informação geográfica americano e métodos estatísticos para estudar a relação entre as variações na concentração de nitrato e os padrões de ocupação urbana e consequente uso do solo no período entre 1971 e 2003.

\section{MATERIAIS E MÉTODOS}

A partir da revisão da literatura até então efetuada com o objetivo de demonstrar que o problema de pesquisa aqui levantado apresenta relevância não apenas em âmbito acadêmico, mas também no cenário das políticas públicas relacionadas ao saneamento básico, foi projetada uma pesquisa de campo com o intuito de verificar e revalidar aquilo que foi apontado até o momento em trabalhos anteriormente realizados especificamente no município de Presidente Prudente, entre os quais se destacam as já citadas pesquisas de Godoy et al. (2004) e Guerra (2011).

Entretanto, determinado o objetivo de elucidar o problema de pesquisa com o enfoque específico no município de Presidente Prudente, optou-se por restringir a pesquisa de campo à zona leste do município, haja vista que, conforme especificado 
anteriormente, configura-se tal região como um polo de urbanização posterior, em consequência de suas características geográficas desfavoráveis à instalação residencial e comercial, principalmente no que tange ao relevo com inclinações acentuadas quando comparado com as demais zonas urbanas prudentinas (MARISCO, 2003, p. 112; HONDA, 2011, p. 86). Assim, obteve-se como área de estudo o polígono desenhado na Figura 2.

A título exemplificativo, elenca-se alguns bairros que compõem a região estudada (PRESIDENTE PRUDENTE, 2019, p. 1):
- Jardim Itapura I e II;

- Residencial Itapoã;

- Jardim Sumaré;

- Residencial Colina do Sol;

- Jardim Vista Bonita;

- Terras de Imoplan;

- Chácaras Filadélfia;

- Chácaras Aguiar;

- Distrito Industrial;

- Jardim Paraíso;

- Vila Aurélio;

- Vila Nova Prudente.

Figura 2. Mapa da área de Estudo. Fonte: (Google, 2018).

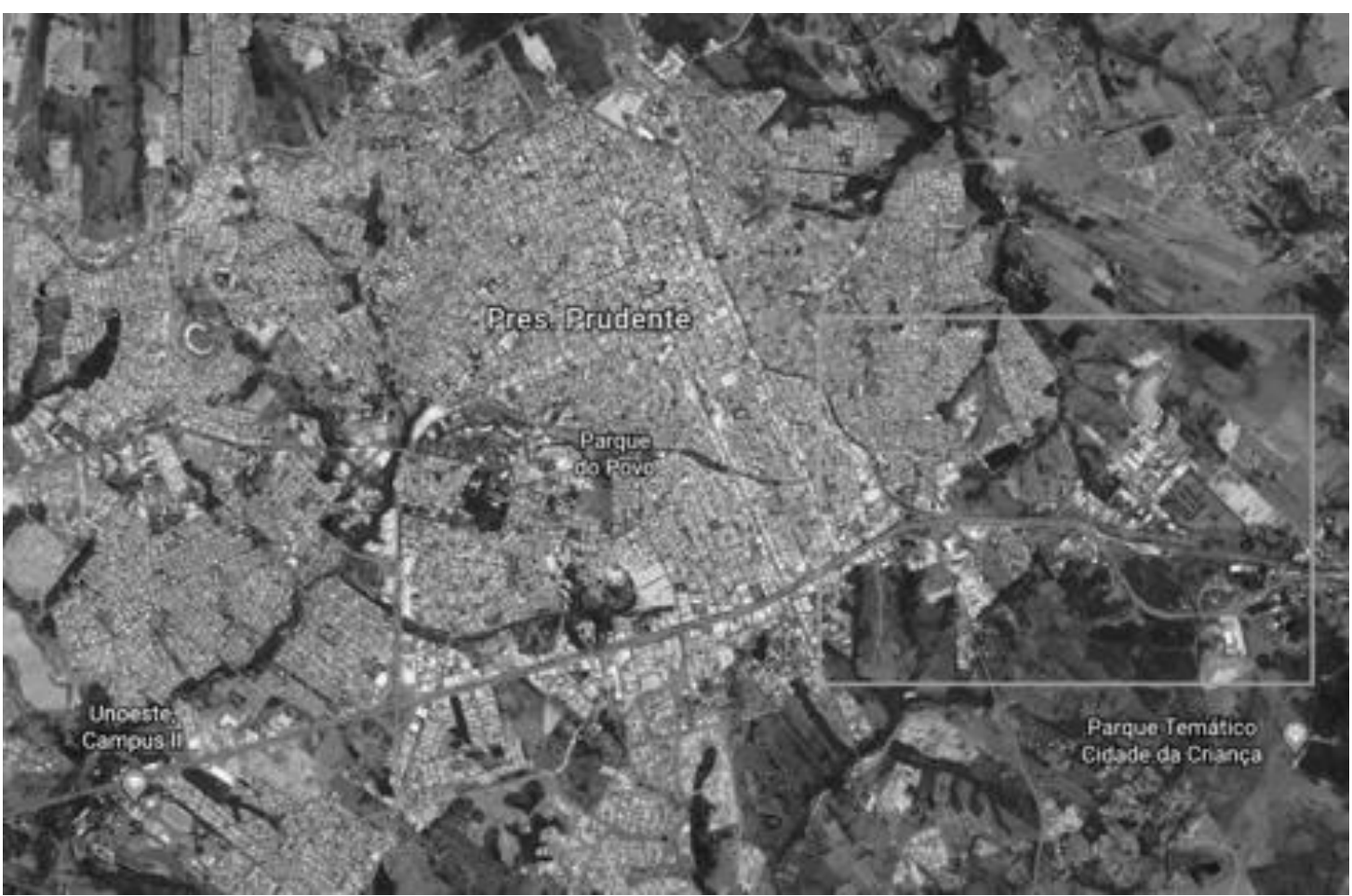


A escolha dos pontos de coleta existentes na área de estudo acima delimitada foi realizada a partir de consulta ao arquivo do Sistema de Informação de Águas Subterrâneas (SIDAS) do Departamento de Águas e Energia Elétrica de São Paulo (DAEE-SP), bem como via consulta à base de dados da Companhia de Saneamento Básico de São Paulo (Sabesp).

Tais consultas revelaram a existência de 353 poços. A partir da disponibilização das coordenadas geográficas dos poços pelo DAEE-SP (2018, p. 1), foi feita a sua inserção no software Google Earth Pro, usando-se como auxílio o software QGIS, o qual possibilitou o mapeamento dos poços dentro da área de estudo determinada.

As visitas de campo a todos os poços acima, com o objetivo de se verificar as possibilidades de coleta das águas, foram realizadas entre os dias 03 e 13 de setembro de 2018. Como resultado, diagnosticou-se que 17 poços eram passíveis de coleta.

Na sequência do trabalho, iniciou-se o cumprimento das etapas preparatórias à realização da coleta, o que se deu no decorrer do mês de outubro de 2018.
Para tanto, definiu-se os seguintes parâmetros químicos e microbiológicos a serem analisados nas águas coletadas:

1. pH apresentado pela água;

2. Condutividade elétrica;

3. Nitrato;

4. Nitrito;

5. Nitrogênio Amoniacal;

6. Nitrogênio Albuminoide;

7. Presença de coliformes totais;

8. Presença da Escherichia coli como indicador de coliformes fecais termotolerantes;

9. Presença de bactérias heterotróficas como determinantes da qualidade bacteriológica das águas de maneira ampla.

Cumpridas as fases preparatórias de cada amostra, se foi a campo em dezembro de 2018, verificando-se a possibilidade de coleta em 12 deles (Figura 3).

Para fins de coleta, denominou-se os poços coletados com números crescentes, que vão de 1 a 12, seguindo-se a ordem acima (Tabela 1).

Figura 3. Pontos de coleta de águas.

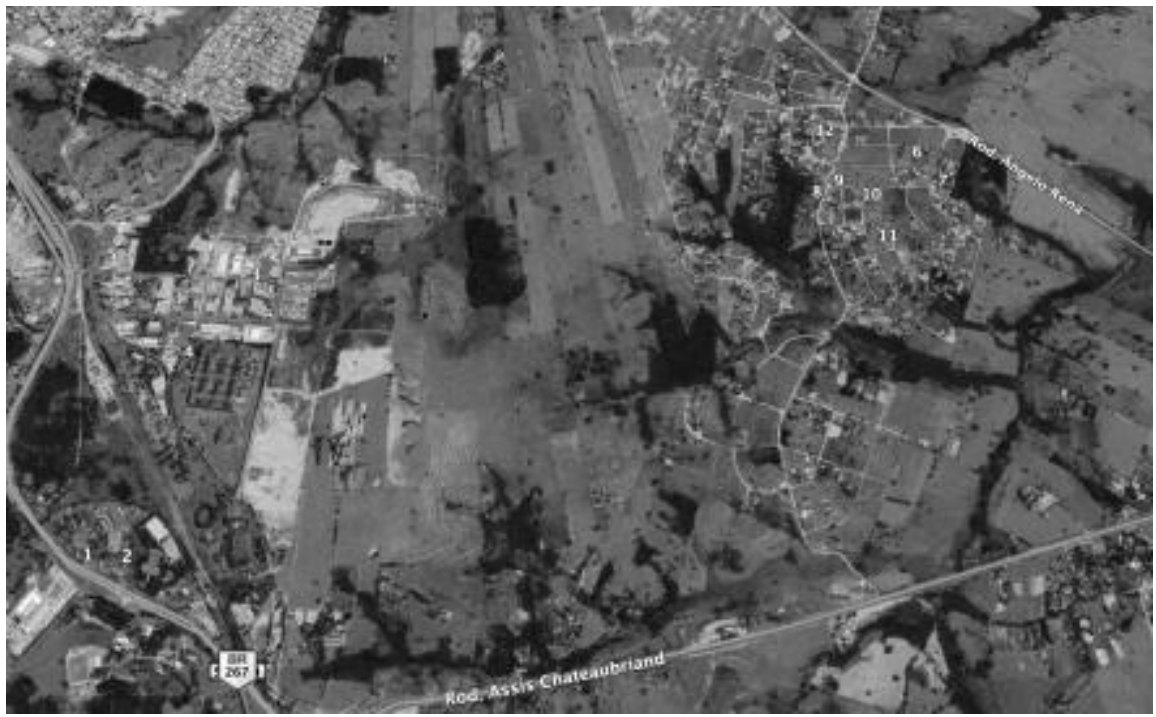

Fonte: (Google, 2019). 
Tabela 1. Detalhes dos pontos de coleta.

\begin{tabular}{|c|c|c|c|c|c|c|c|}
\hline Poço & Latitude & Longitude & Altitude & Cadastrado no DAEE & Código & Nível (m) & Atividade \\
\hline 1 & $22^{\circ} 10^{\prime} 16.78^{\prime \prime S}$ & $51^{\circ} 22^{\prime} 45.54^{\prime \prime} \mathrm{O}$ & $472 \mathrm{~m}$ & Sim & 300 & 44,60 & Unidade de órgão público \\
\hline 3 & $22^{\circ} 09^{\prime} 37.53 " \mathrm{~S}$ & $51^{\circ} 22$ '21.98" O & $464 \mathrm{~m}$ & Sim & 295 & 27,14 & Indústria - areia, pedra e concreto \\
\hline 5 & $22^{\circ} 09^{\prime} 32.26 " \mathrm{~S}$ & $51^{\circ} 22^{\prime} 48.85^{\prime \prime} \mathrm{O}$ & $456 \mathrm{~m}$ & Sim & 365 & Indisponível & Indústria - areia, pedra e concreto \\
\hline 6 & $22^{\circ} 09^{\prime} 17.61^{\prime \prime S}$ & $51^{\circ} 20 ' 37.79^{\prime \prime} \mathrm{O}$ & $447 \mathrm{~m}$ & Não & $\mathrm{N} / \mathrm{A}$ & Indisponível & Chácara residencial \\
\hline 7 & $22^{\circ} 09^{\prime} 17.59^{\prime \prime S}$ & $51^{\circ} 20 ' 33.12^{\prime \prime} \mathrm{O}$ & $445 \mathrm{~m}$ & Não & $\mathrm{N} / \mathrm{A}$ & Indisponível & Chácara residencial \\
\hline 9 & $22^{\circ} 09^{\prime} 22.00 " \mathrm{~S}$ & $51^{\circ} 20^{\prime} 44.94 " \mathrm{O}$ & $441 \mathrm{~m}$ & Não & $\mathrm{N} / \mathrm{A}$ & Indisponível & Chácara residencial \\
\hline 10 & $22^{\circ} 09^{\prime 2} 26.34 " \mathrm{~S}$ & $51^{\circ} 20^{\prime} 42.95^{\prime \prime} \mathrm{O}$ & $437 \mathrm{~m}$ & Não & $\mathrm{N} / \mathrm{A}$ & Indisponível & Chácara residencial \\
\hline 11 & $22^{\circ} 09^{\prime} 30.51 " \mathrm{~S}$ & $51^{\circ} 20^{\prime} 42.88^{\prime \prime O}$ & $433 \mathrm{~m}$ & Não & $\mathrm{N} / \mathrm{A}$ & \begin{tabular}{|l|} 
Indisponível \\
\end{tabular} & Chácara residencial \\
\hline 12 & $22^{\circ} 09^{\prime} 15.39^{\prime \prime S}$ & $51^{\circ} 20^{\prime} 49.97^{\prime \prime} \mathrm{O}$ & $450 \mathrm{~m}$ & Não & $\mathrm{N} / \mathrm{A}$ & Indisponível & Chácara residencial \\
\hline
\end{tabular}

Fonte: (DAEE-SP, 2018; GOOGLE, 2018).

Saiu-se do laboratório com os frascos de um litro esterilizados por meio do aparelho autoclave de marca Baumer, juntamente com um saco de gelo de cinco quilos adquirido antes do início das coletas. Também se levou uma caixa térmica de isopor adquirida para este fim específico de armazenar os frascos com as amostras coletadas.

Chegando-se a cada poço, tem-se que a amostragem foi realizada através das próprias bombas instaladas em cada um dos poços. Inicialmente, contudo, se realizou a purga prévia para remoção de água estagnada e a esterilização das torneiras com o uso de gaze e álcool $70 \%$.

Levadas a laboratório após a coleta e seu acondicionamento, as amostras foram submetidas para análise direcionada à identificação dos parâmetros químicos e microbiológicos definidos previamente e já aqui elencados.

Todas as análises foram efetuadas em duplicatas, sendo considerado o valor de sua média para fins de inserção nos resultados e posterior construção de análises e comparativos.

Como ponto de partida, tomou-se os padrões metodológicos internacionalmente reconhecidos e adotados para análise de águas, estes derivados do manual produzido pela American Public Health Association, denominado Standard Methods For The Examination of Water And Wastewater (EATON et al., 2005).

Tais padrões foram utilizados na determinação do nitrito e do nitrogênio amoniacal. Especificamente para o Nitrato foi utilizado espectrofotômetro da marca Hach e kit de teste com sachês para análise de Nitrato (leitura direta). O nitrogênio albuminoide, por sua vez, foi determinado a partir de metodologia própria do Instituto Adolfo Lutz (INSTITUTO ADOLFO LUTZ, 1985, p. 315), nas características determinadas adiante

Tem-se, contudo, a observar, que os parâmetros acima mencionados foram determinados com característica comum, a saber, o estabelecimento da curva de calibração e da posterior dosagem através de métodos colorimétricos. Para a construção de tais curvas, adotou-se cinco concentrações e mediu-se as respectivas absorbâncias por meio do espectrofotômetro visível de marca Quimis, dada a existência de correlação entre absorbância e concentração, nos termos da Lei de Lambert-Beer. Excepciona-se, como mencionado, o nitrato, que teve sua determinação a partir da realização de leitura direta com o uso de kits de teste com sachês.

No caso do nitrogênio albuminoide, utilizou-se, conforme a metodologia estabelecida pelo Instituto Adolfo Lutz (1985, p. 315), a curva padrão preestabelecida com soluções padrão de cloreto de amônio, multiplicando-se o resultado pelo fator 0,2 , correspondente à alíquota de $50 \mathrm{ml}$ tomada de um balão volumétrico de $100 \mathrm{ml}$ contendo o destilado de $500 \mathrm{ml}$ da amostra.

Os coliformes totais, Escherichia coli e contagem de bactérias heterotróficas foram realizados com a técnica da membrana 
filtrante e cultura em meio ágar seletivo, de modo que, após o período de incubação, considerado como sendo 24 horas após a colocação na estufa, realizou-se a contagem das colônias com a adoção dos seguintes moldes:

- Colônias vermelhas e salmão: identificação dos coliformes totais;

- Colônias azuis e pretas: identificação de coliformes fecais, especificamente a Escherichia coli;

- Colônias amarelas: contagem de bactérias heterotróficas.

$\mathrm{O} \mathrm{pH}$, por sua vez, foi determinado potenciometricamente com a utilização de equipamento pHmetro de marca Quimis, ao passo que a Condutividade foi determinada por análise direta utilizando condutivímetro de marca Hanna Instruments, tendo se considerado a escala de 0 - 1999,0 $\mu \mathrm{s} / \mathrm{cm}$.

Para cada um dos parâmetros identificados, necessário se fez adotar um valor de referência, com o qual se pudesse comparar o valor identificado na pesquisa e assim se inferir se as águas dos poços apresentavam ou não níveis superiores com relação àquele determinado parâmetro (Quadro 1).

Quadro 1. Valores Máximos Permitidos para cada parâmetro estudado.

\begin{tabular}{|l|l|l|}
\hline \multicolumn{1}{|c|}{ Parâmetro Estudado } & \multicolumn{1}{|c|}{ Valor Máximo Permitido } & \multicolumn{1}{c|}{ Fonte } \\
\hline $\mathrm{pH}$ & Recomendação entre 6,00 e 9,50 & Portaria 2914/2011 do Ministério da Saúde (BRASIL, 2011). \\
\hline Condutividade Elétrica & $10 \mathrm{a} 100 \mathrm{\mu s} / \mathrm{cm}$ & FONSECA, 2017, p. 22 \\
\hline Nitrato & $10,00 \mathrm{mg} \mathrm{NO3-/L} \mathrm{N}$ & $\begin{array}{l}\text { Resolução 396/2008 do CONAMA (BRASIL, 2008); } \\
\text { Portaria 2914/2011 do Ministério da Saúde (BRASIL, 2011). }\end{array}$ \\
\hline Nitrito & $1,00 \mathrm{mg} \mathrm{NO2-/L} \mathrm{N}$ & $\begin{array}{l}\text { Resolução 396/2008 do CONAMA (BRASIL, 2008); } \\
\text { Portaria 2914/2011 do Ministério da Saúde (BRASIL, 2011). }\end{array}$ \\
\hline Nitrogênio Amoniacal & $1,50 \mathrm{mg} / \mathrm{L} \mathrm{N}$ & $\begin{array}{l}\text { Resolução 396/2008 do CONAMA (BRASIL, 2008); } \\
\text { Portaria 2914/2011 do Ministério da Saúde (BRASIL, 2011). }\end{array}$ \\
\hline Nitrogênio Albuminoide & $0,08 \mathrm{mg} / \mathrm{L} \mathrm{N}$ & INSTITUTO ADOLFO LUTZ, 1985, p. 315 \\
\hline Coliformes Totais & Ausência em 100 ml & Portaria 2914/2011 do Ministério da Saúde (BRASIL, 2011). \\
\hline Escherichia coli & Ausência em 100 ml & Portaria 2914/2011 do Ministério da Saúde (BRASIL, 2011). \\
\hline Bactérias Heterotróficas & $500 \mathrm{UFC} / \mathrm{ml}$ & Portaria 2914/2011 do Ministério da Saúde (BRASIL, 2011). \\
\hline
\end{tabular}

Fonte: (O Autor, 2019).

Aplicando-se a metodologia descrita até o presente momento, procedeu-se com o tratamento estatístico mediante análises descritivas convencionais. Tal tratamento foi feito com o objetivo de avaliar o comportamento relativo entre os diferentes compostos presentes na água e as possíveis causas de sua presença.

A análise estatística convencional se baseou na determinação da média aritmética simples, da variância e do desvio padrão. As determinações destas variáveis definiram os valores médios de cada parâmetro para as duas campanhas de amostragem, juntamente com as medidas clássicas de dispersão.

Adicionalmente, com 0 intuito específico de dimensionar a dispersão ou variabilidade dos dados em termos relativos ao seu valor médio, foi também calculado o coeficiente de variação de Pearson (CVP). Tal coeficiente deriva da razão entre o desvio padrão e a média referente a cada um dos parâmetros analisados.

\section{RESULTADOS E DISCUSSÃO}

A presente pesquisa foi realizada no sentido de confirmar a contaminação de poços de captação de águas pelos elementos de referência e seu consequente retorno para consumo das populações locais, persistindo-se o problema até os dias atuais, de modo que as regiões com saneamento básico recente ou inexistente (notadamente pontos da zona leste de Presidente Prudente) ainda se utilizam de tanques sépticos e poços, o que vem a ocasionar a presença de compostos químicos e microbiológicos nas águas subterrâneas.

Desta forma, os resultados obtidos foram, assim, comparados com os Valores Máximos Permitidos para os parâmetros químicos e microbiológicos analisados, nos 
termos do Quadro 1, de modo a se determinar se há ou não o enquadramento ao estabelecido nas normas regulamentadoras e recomendações bibliográficas para tais parâmetros no que tange às águas para uso e consumo humanos.

A Tabela 2 demonstra a análise estatística convencional de cada parâmetro.

Tabela 2. Análise estatística convencional de cada parâmetro.

\begin{tabular}{|c|c|c|c|c|c|c|c|c|c|}
\hline & pH & Condutividade & Nitrato & Nitrito & $\begin{array}{c}\text { Nitrogênio } \\
\text { Amoniacal }\end{array}$ & $\begin{array}{c}\text { Nitrogênio } \\
\text { Albuminoide }\end{array}$ & $\begin{array}{c}\text { Coliformes } \\
\text { totais }\end{array}$ & E-coli & $\begin{array}{c}\text { Bactérias } \\
\text { heterotróficas }\end{array}$ \\
\hline Média & 6,66 & 162,75 & 4,60 & 0,01 & 0,19 & 0,08 & 8,08 & 0,25 & 9,83 \\
\hline Variância & 0,06 & 2388,75 & 5,49 & 0,00 & 0,00 & 0,00 & 433,17 & 0,20 & 299,42 \\
\hline Desvio Padrão & 0,24 & 48,87 & 2,34 & 0,00 & 0,02 & 0,02 & 20,81 & 0,45 & 17,30 \\
\hline Coef. Variação & 0,04 & 0,30 & 0,51 & 0,36 & 0,11 & 0,20 & 2,57 & 1,81 & 1,76 \\
\hline
\end{tabular}

Fonte: (O Autor, 2019).

Nos termos expostos, verifica-se que o parâmetro $\mathrm{pH}$ se apresentou dentro das recomendações da Portaria 2914, de 2011, do Ministério da Saúde (BRASIL, 2011), que em seu artigo 39 recomenda que as águas apropriadas para consumo humano apresentem o pH na faixa de 6,0 a 9,5.

O parâmetro condutividade, por sua vez, supera razoavelmente os Valores Máximos Permitidos, ao passo que os

Figura 4. Gráficos dos parâmetros relacionados ao nitrogênio.
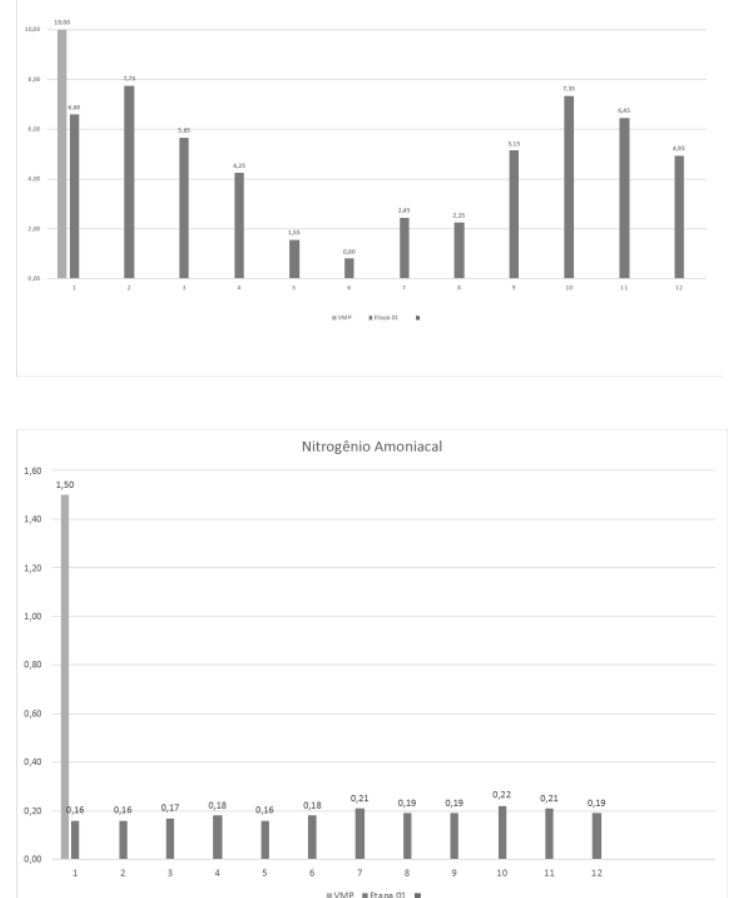

Fonte: (O Autor, 2019). parâmetros relacionados ao nitrogênio (nitrito, nitrato, nitrogênio amoniacal e nitrogênio albuminoide), como visto, ficaram dentro dos níveis permitidos, à exceção do nitrogênio albuminoide que apresenta três poços cujas águas estão com quantidades acima do permitido (Figura 4).

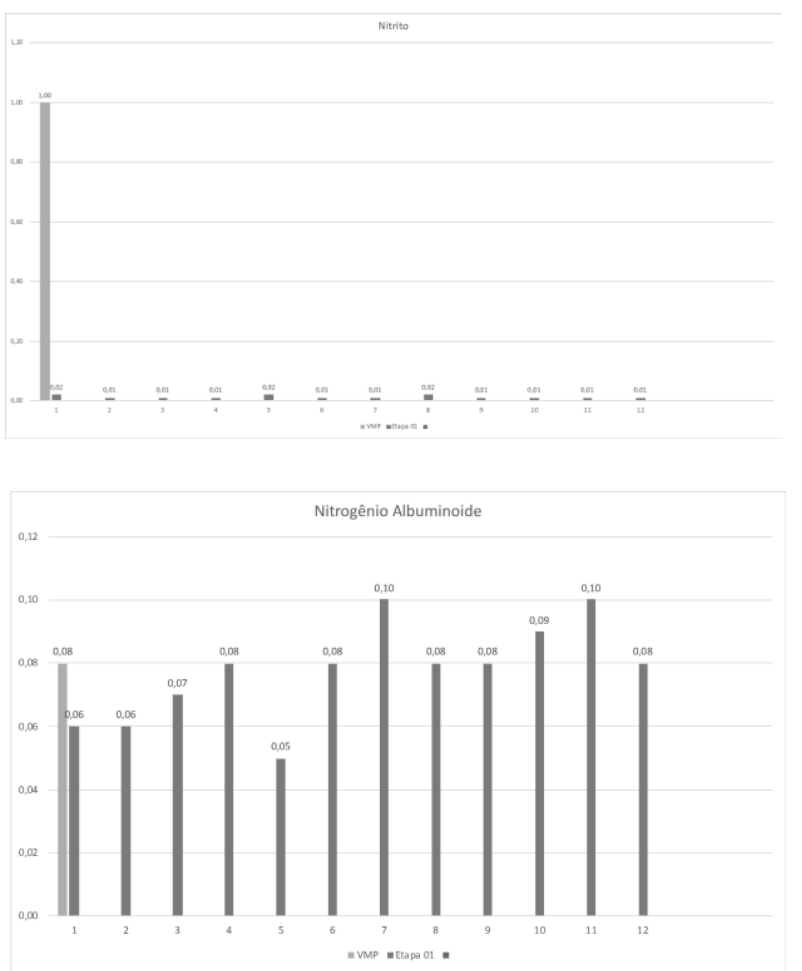


Desta forma, discutindo-se os resultados no que tange aos parâmetros relacionados ao nitrogênio, a revisão bibliográfica efetuada neste trabalho demonstrou que a sua presença nas águas destinadas ao consumo humano, em diferentes estados de oxidação, é indicativa de contaminação dos poços de captação de águas e de possíveis condições higiênico sanitárias insatisfatórias. $\mathrm{O}$ nitrito e o nitrato estão associados a dois efeitos adversos à saúde: a indução à metahemoglobinemia e a formação potencial de nitrosaminas e nitrosamidas carcinogênicas.

Portanto, especificamente no que tange ao nitrato, Alaburda e Nishihara (1998, p. 163), informam haver autores que consideram que concentrações superiores a 3 miligramas de nitrato por litro são indicativos de contaminação devido às atividades antropogênicas. Partindo-se deste princípio, pode-se inferir que o ideal seria que as concentrações dos parâmetros relativos às séries nitrogenadas ficassem o mais próximo possível de zero.

Especificamente quanto à relação dos parâmetros encontrados com as atividades existentes nos locais de coleta, cumpre destacar, nos termos de Fonseca (2017, p. 18) que o nitrogênio albuminoide remete ao início do processo de oxidação do nitrogênio, que virá a produzir o nitrito e o nitrato. Sua presença remete ao contato recente da água com excretas, de modo que ainda não houve o início do processo de degradação da matéria orgânica.

Observa-se que os parâmetros microbiológicos também apresentaram níveis passiveis de consideração, uma vez que ocorreu a superação dos Valores Máximos Permitidos em algumas ocasiões (Figura 5).

Figura 5. Gráficos dos parâmetros microbiológicos analisados.

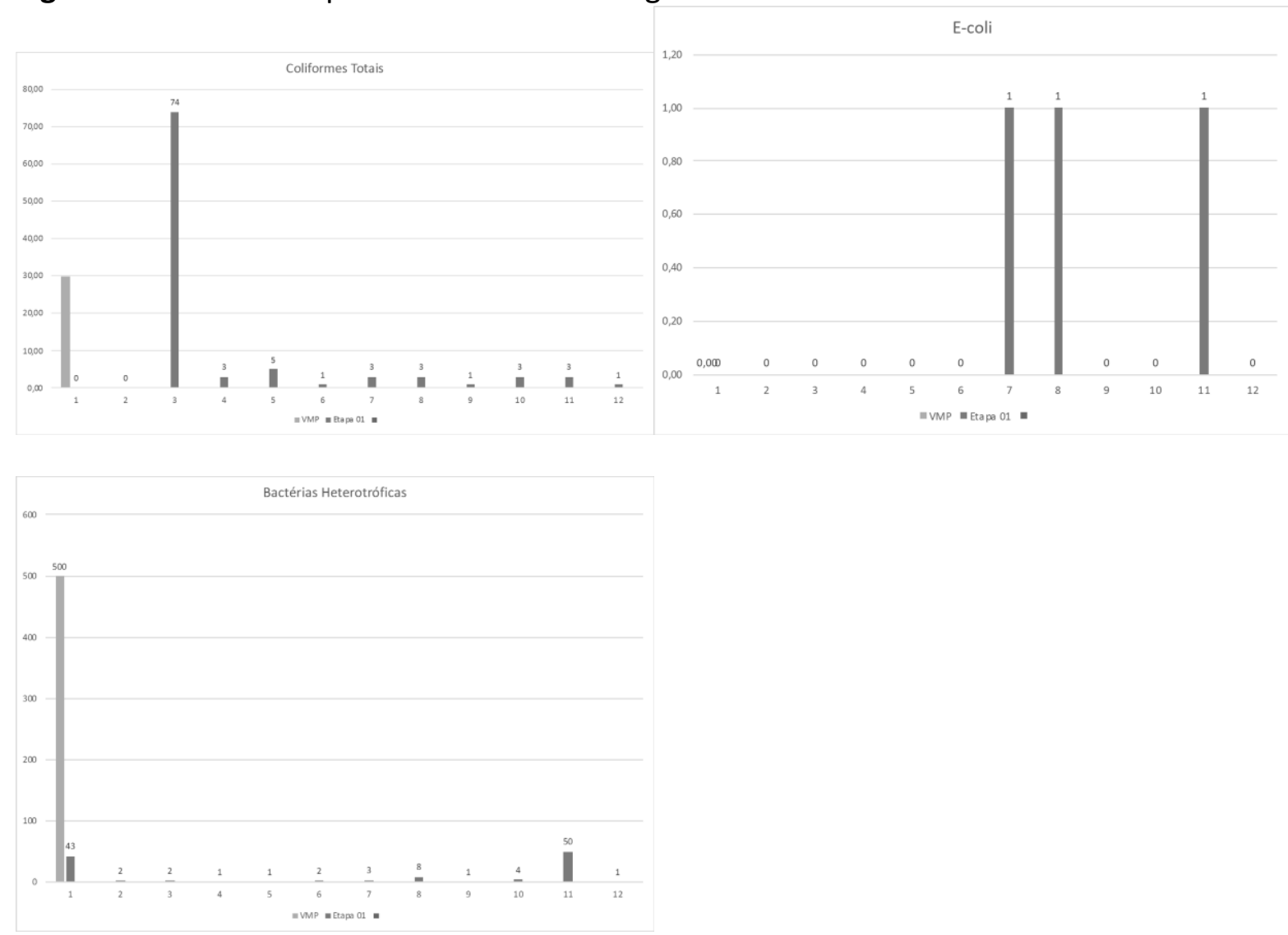

Fonte: (O Autor, 2019). 
Portanto, na análise dos parâmetros ora em tela, verifica-se a sua existência, ficando patente, assim, a impropriedade de parte das águas para consumo humano, haja vista o desrespeito aos valores máximos adotados para cada um dos referidos parâmetros, nos termos da Portaria 2914/2011 do Ministério da Saúde. Assim, recomenda-se que as águas com parâmetros acima dos valores máximos permitidos não sejam consumidas, mesmo porque, no que diz respeito aos coliformes totais e à $E$-coli, a mera presença de qualquer quantidade já configura a impropriedade do ambiente.

Em síntese, de posse dos resultados apresentados e de seu respectivo detalhamento aqui efetuado, bem como das visitas de campo realizadas, pode-se extrair que as regiões pesquisadas de fato seguem com saneamento básico precário. No Distrito Industrial, onde se encontram os poços de 1 a 5 , já existe o saneamento básico, contudo boa parte das empresas lá sediadas ainda mantêm os poços em plena utilização.

Por outro lado, nos bairros rurais visitados, de onde se extraiu as águas dos poços de 6 a 12, não existe saneamento básico, fato este constatado pelas condições locais e pelos poços em pleno funcionamento no ato da coleta das águas.

\section{CONSIDERAÇÕES FINAIS}

Presidente Prudente, sendo um município de porte médio caracterizado por um processo de urbanização com planejamento falho, abre um leque bastante interessante para pesquisadores que queiram se aventurar a entender as minúcias de sua expansão geográfica em território urbano, como era a pretensão deste projeto de pesquisa quando foi iniciado com o intuito de melhor compreender a região leste no que tange especificamente ao seu saneamento básico.

Em tal contexto, quando se efetuou a revisão bibliográfica e se partiu para os trabalhos de campo destinados a confirmar ou refutar as hipóteses inicialmente traçadas, foi possível se ter a dimensão da amplitude dos problemas pelos quais o município ainda passa. O contato com zonas distantes das áreas centrais, nas quais vivem prudentinos em condições precárias certamente foi importante para transformar as visões do pesquisador quando se viu frente a frente com realidade diferente da sua, ainda que distante apenas poucos quilômetros.

Em se tratando especificamente dos resultados alcançados e das conclusões extraídas, tem-se que a qualidade das águas, no geral, ainda é imprópria para o consumo humano. Por mais que os nove parâmetros anotados para cada um dos doze poços não apontem níveis tão destoantes dos Valores Máximos Permitidos, é fato que não existem condições sanitárias adequadas para uma população que contribui com suas obrigações enquanto cidadãos. Afinal, a utilização de tanques sépticos e poços é hábito que já não deveria mais fazer parte do cotidiano de pessoas e empresas em pleno século XXI.

Considera-se, portanto, que subsiste o saneamento in situ em regiões periféricas do município de Presidente, como demonstram as evidências retratadas no escopo deste trabalho, ainda que sua limitação tenha se dado em uma área previamente recortada para pesquisa.

\section{AGRADECIMENTOS}

Os autores agradecem ao CBH-PP Comitê da Bacia Hidrográfica do Pontal do Paranapanema, ao DAEE/SP - Departamento de Água e Energia Elétrica do Estado de São Paulo e, por fim, aos Laboratórios de Química da Universidade do Oeste Paulista (UNOESTE).

\section{REFERÊNCIAS}

ALABURDA, J.; NISHIHARA, L., Presença de compostos de nitrogênio em águas de poços. Revista de Saúde Pública, São Paulo, v. 32, n. 2, p. 160-165, abr. 1998. https://doi.org/10.1590/\$0034$\underline{89101998000200009}$ $\begin{array}{lllr}\text { ALBANO, M. } & \text { P. A importância } & \text { do } \\ \text { planejamento } & \text { urbano } & \text { ambiental: } & \text { a }\end{array}$ 
habitação social e a expansão urbana em Presidente Prudente-SP. 2013. 166 f. Dissertação (Mestrado em Meio Ambiente e Desenvolvimento Regional) - Universidade do Oeste Paulista, Presidente Prudente, 2013.

CAGNON, F. A. Origem e hidroquímica do nitrato nas águas subterrâneas do Aquífero Adamantina em Urânia, SP. 2003. 148 f. Dissertação (Mestrado em Geografia) Instituto de Geociências, Universidade de São Paulo, São Paulo, 2003.

DRAKE, V. M.; BAUDER, J. W. Ground water nitrate-nitrogen trends in relation to urban development, Ground Water Monitoring and Remediation, Helena Montana, v. 25, n. 2, p. 118-130, mar. 2005. https://doi.org/10.1111/j.17456592.2005.0017.x

EATON, A. D. et al. Standard Methods for the Examination of Water and Wastewater. 21st ed. Washington: American Public Health Association, American Water Works Association and Water Environment Federation, 2005.

FONSECA, A. L. Determinação do Índice de Nitrato, Nitrito e Nitrogênio Amoniacal na Água da Lagoa de Extremoz/RN. 2017. 48 f. Trabalho de Conclusão de Curso (Graduação em Química) - Instituto de Química, Universidade Federal do Rio Grande do Norte, Natal, 2017.

FOSTER, S.; HIRATA, R. Groundwater pollution risk assessment: a methodology using available data. World/Pan American Health Organization - CEPIS Technical Report: Lima, Perú, 1988.

GODOY, M. C. T. F. et al. Contaminação das águas subterrâneas por nitrato em Presidente Prudente - SP, Brasil. Revista Instituto Adolfo Lutz, São Paulo, v. 63, n. 2, p. 208-214, abr. 2004.
GOOGLE Earth Pro (Mac). Versão 7.3: Google Corporation, 2018.

GUERRA, S. H. P. Contaminação por nitrato e sua relação com o crescimento urbano no sistema aquífero Bauru em Presidente Prudente (SP). 2011. 148 f. Dissertação (Mestrado em Geografia) - Instituto de Geociências, Universidade de São Paulo, São Paulo, 2011.

HIGITEC. O que é uma fossa negra? 2017. Disponível em: < https://www.higitec. com.br/blog/o-que-e-uma-fossa-negra/>.

Acesso em: 02 fev. 2019.

HONDA, S. C. A. L. Habitação de baixa renda como produto do capital: o Programa de Arrendamento Residencial (PAR) em Presidente Prudente. 2011. 189 f. Tese (Doutorado em Arquitetura) - Faculdade de Arquitetura e Urbanismo, Universidade Presbiteriana Mackenzie. São Paulo, 2011.

HONDA, S. C. A. L. et al. Planejamento ambiental e ocupação do solo urbano em Presidente Prudente (SP). Revista Brasileira de Gestão Urbana (Brazilian Journal of Urban Management). Curitiba, v. 7, n. 1, p. 62-73, fev. 2015. https://doi.org/10.1590/21753369.007.001.AO04

IBGE. Instituto Brasileiro de Geografia e Estatística. Informações sobre os Municípios Brasileiros. 2016. Disponível em: http://cidades.ibge.gov.br/xtras/perf il.php?codmun=354140. Acesso em: 14 abr. 2017.

IBGE. Instituto Brasileiro de Geografia e Estatística Informações sobre os Municípios Brasileiros - Presidente Prudente. 2019. Disponível em: https://cidades.ibge.gov.br/brasil/sp/ presidente-prudente/panorama. Acesso em: 26 jan. 2019. 
INSTITUTO ADOLFO LUTZ. Normas Analíticas do Instituto Adolfo Lutz. v.1: Métodos químicos e físicos para análise de alimentos. 3. ed. São Paulo: IMESP, 1985.

MARISCO, L. M. O. A Norma e o Fato: abordagem analítica da segregação socioespacial e exclusão social a partir dos instrumentos urbanísticos. 2003. 212 f. Tese (Doutorado em Geografia) - Faculdade de Ciência e Tecnologia, Universidade Estadual Paulista, Presidente Prudente, 2003.

PREFEITURA MUNICIPAL DE PRESIDENTE PRUDENTE. Sabesp universaliza saneamento básico em Presidente Prudente. 2018. Disponível em: http://www. presidenteprudente.sp.gov.br/site/noticias.x html?cod=40382. Acesso em: 26 jan. 2019.

PREFEITURA MUNICIPAL DE PRESIDENTE PRUDENTE. Mapas e informações geográficas, 2019. Disponível em: http://www.presidenteprudente.sp.gov.br/si te/ central_mapas.xhtml. Acesso em: 02 fev. 2019.

SÃO PAULO (Estado). Departamento de Águas e Energia Elétrica. Portarias 1630 a 1636 de 30 de maio de 2017. Disponível em: http://www.daee.sp.gov.br/index.php?opt ion $=$ com_content $\&$ view $=$ article $\&$ id $=1636 \% 3 \mathrm{~A}$ novo-portaloutorgas\&catid=72\%3Anovo portal-de-outorgas\&ltemid=79. Acesso em: 22 abr. 2018.

SÃO PAULO (Estado). Departamento de Águas e Energia Elétrica. Pesquisa de Poços. $2018 . \quad$ Disponível em: http://www.aplicacoes.daee.sp.gov.br/usosr ec/Daeewebpoco .html. Acesso em: 22 abr. 2018.

VARNIER, C. 0 efeito do nitrogênio proveniente de sistemas de saneamento in situ na qualidade das águas subterrâneas em aquíferos livres e rasos. 2001. Dissertação (Mestrado). 150 f. Dissertação (Mestrado em Química) - Instituto de
Geociências, Universidade de São Paulo, São Paulo, 2001.

WAKIDA, F. T.; LERNER, D. N. Non-agricultural sources of groundwater nitrate: a review and case study. Rev. Water Research, Londres, v. 39, n. 1, p. 3-16, jul. 2005. https://doi.org/10.1016/j.watres.2004.07.02 $\underline{6}$ 